\title{
Putative Polycomb Group Protein ASXL1
}

National Cancer Institute

\section{Source}

National Cancer Institute. Putative Polycomb Group Protein ASXL1. NCI Thesaurus. Code C97322.

Putative Polycomb group protein ASXL1 (1541 aa, 165 kDa) is encoded by the human ASXL1 gene. This protein may be involved in the modulation of both transcription and chromatin remodeling. 